\title{
ANALYSIS OF TIK-TOK VIDEO'S COMPETITIVE FACTORS USING A COMPREHENSIVE MULTILEVEL FUZZY EVALUATION METHOD
}

\author{
Zoltán PEREDY \\ Engineering Institute, Edutus University Tatabánya, Hungary \\ Feierzhati FUKATI
}

Faculty of Business Administration and Management, Edutus University, Hungary

Balázs LAKI

Engineering Institute, Edutus University Tatabánya, Hungary

Received: 29. November 2020, Reviewed:23. December 2020, Accepted: 30. December 2020

\begin{abstract}
Due to the emerging current globalization trends (Industry 4.0., Digitization, Artificial Intelligence, and Disruptive Technologies) and the unprecedented accompanying social challenges, new network media solutions are becoming increasingly powerful. The short video industry will have more opportunities, while market competition will be increasingly stronger. The competition between enterprises is essentially the competition of core competitiveness. This paper focuses on Tik-Tok (in China Douyin) short video and it studies the core competence of Douyin short video from four aspects: international development ability, cultural communication ability, technology research and development ability and profit generation ability. Starting from the introduction and analysis of core competence theories, the short video industry and particularly Douyin short video will be overviewed, including its current business environment. Multilevel fuzzy comprehensive evaluation was used to test the core competitiveness of Douyin short video. The final aim is to obtain specific measures in order to enhance its core competitiveness through the above methods including future challenges (how to strictly distinguish between entertainment and trading, the homogeneity of video recommendation categories, network security and supervision). Besides that, at the same time, its social, and business opportunities (new realization mode, obtaining better traffic, creating more social value to promote economic development, knowledge popularization) will be analysed.
\end{abstract}

Keywords: multilevel fuzzy evaluation, core competencies, Douyin short video, business opportunities

JEL Classification: O33; F0; C690 


\section{Introduction}

Short video is an alternative content output form, and it can serve as a common social online platform for the new generation of Internet users. According to Trzcińskiet al. (2017), half of all Internet users prefer different short-video applications. Short videos with their length of time, new content, fast update, fragmentation and with their other characteristics meet the newly emerging demands of the online consumer market reaching maximum client satisfaction.

With the rapid development of $5 \mathrm{G}$ technology, the transmission of short videos has been promoted. It can be expected that $5 \mathrm{G}$ technology will become the support of short video technology of network service providers, and will bring explosive growth to the short video industry. The first Internet companies that find new ideas and new models for short video transmission in the 5G era will become the new industry leaders. On the other hand, short videos also influence people's thoughts, views and values.

The short video industry will provide new opportunities, while market competition will be increasingly stronger. The competition between enterprises is essentially the competition of core competitiveness. This paper focuses on Tik-Tok (in China Douyin) short video and studies the core competence of Douyin short video from four aspects: international development ability, cultural communication ability, technology research and development ability and profit generation ability.

\section{Theoretical background}

Short video on a mobile terminal refers to short videos that users shoot, edit and upload to the Internet for wide dissemination by using a mobile terminal with a media platform, with rich specific styles (Krishnan \& Sitaraman, 2013). The content covers the sharing of daily life, relaxing, entertainment, current events and hot spots, and they last for more than 5 minutes, and are fragmented. They usually refer to videos that are carried by smart mobile devices, they are easy and convenient to shoot, edit and produce, and can realize the strong social attribute of sharing and dissemination (Chen\& Lee, 2014). Short we-media videos from the mobile end can be divided into two categories according to different transmission sources. One is the copy image from the network, which is transmitted through mobile social media, namely "forward video". In this case, the key to the forwarding behaviour is to draw the audience's attention. In terms of life, work and feelings, this kind of video can often initiate discussion among the groups interested in the relevant content (Gygli, Song, \& Cao, 2016). The other is images created by individual communicators, which are edited, beautified and uploaded to the Internet for sharing, which is called "homemade video" (Granic, Lobel, \& Engels, 2014). The dissemination is not restricted by time and place, and no one knows when dissemination will stop. It is often difficult for traditional media to maintain high interaction times, modes and scales in the transmission process (Masiar\& Simko, 2015). The spread of home-made videos can be related to the social platform which is more than software, because the video content as a product is easily and quickly adjustable to the societal circumstances impacted by the individual user habit. For this reason, online homemade video content production is also divided into Professionally Generated Content (PGC) and User Generated Content (UGC). UGC videos, represented mainly by Kuaishou videos, are produced and uploaded by users themselves, and most of the short videos come from ordinary 
users. As an example of PGC videos, MiaoPai videos could be mentioned, who pay more attention to professional content. The videos are made usually by professional teams or individuals, and tend to spread professional content for the operation of the platform (Winkler et al., 2017). The former occupies a dominant position in the content dissemination of social platforms, while the latter one is a content production situation of various traditional media.

Both the transmitting and receiving parties have the right to communicate actively (Green, Bobrowicz, \& Ang, 2015). In the communication process, short videos on mobile terminals integrate different types of communication, such as interpersonal communication, group communication and mass communication. The videos have their own characteristics, such as they are personalized, social, and diversified, which further enriches the content spread on the network. In the Internet era, the needs of users are always changing and dynamic. Different audiences have different needs at different times. There are demands for entertainment, leisure and social contact. Short videos on mobile terminals are one of the many forms of information transmission, which evolved from interpersonal communication in real life and is a process of media content sharing and feedback (Gulacti, Lok, Hatipoglu, \& Polat, 2016).

The popularity of short video apps on mobile terminals enables ordinary users to make and edit videos online on mobile terminals, and to add text and music to videos. At present, Kuaishou, Douyin, Micro-vision and Miaopai are four popular short video social apps in the mobile short video application market (Li, 2018).

TikTok and its Chinese version Douyin are the world's most lucrative apps and both apps are made by Bytedance, a Beijing-based internet company. The most prevalent short video platform or APP in China is Douyin Short Video (Douyin), released on September 26, 2016. In mid-July 2018, Douyin officially announced that the number of their active monthly users had exceeded 500 million globally, ranking them the first in the number of users (Ma et al., 2019). Users of Douyin short video can make videos more enjoyable by shooting short videos, adding technical features such as filters, video effects, scene switching, etc., and thus making the short videos have a strong sense of trend through the shooting and processing of smart seconds supplemented also by music.

TikTok short video was launched in September 2016 as a 15-second video short video sharing community. The main theme is "music and UGC" cell-phone short video. A trill short video app is defined as a social app software, it focuses on the younger generation, where users can select music, supplemented by a short video. Users can create their own short video (Wang, Gu, \& Wang, 2019). In 2018, TikTok experienced a rapid development, and it is now one of the most popular short video mobile apps in Vietnam, Indonesia, India, Japan, Thailand, Germany and other countries (Wang, 2020a). At present, TikTok short video has entered more than 150 countries and regions. In more than 40 countries, app stores rank it in the top 10, including the APP STORE under IOS system and the mobile STORE under the android system. TikTok short video is also the fastest growing mobile short video APP in the world. In TikTok's 2018 report, released in January 2019, TikTok's daily active users in China exceeded 250 million (250 million DAU-Daily Active User) and its monthly active users in China exceeded 500 million (500 million DAU). The TikTok app has been downloaded over 1.5 billion times worldwide. The average user spends 52 minutes per day on the TikTok app. Almost $50 \%$ of TikTok's global audience is under the age of $34.26 \%$ of all TikTok users are aged between 18 and 24. In June 2020, teenagers accounted for 32 percent of TikTok's active user accounts (Wang, 2020a and 2020b). 
What can be the possible driving forces beyond these trends? Diversified ways of communication: the content of short videos on mobile terminals is more powerful than the traditional figures and texts, which can raise the interest of the audience and achieve a good communication effect. The platform provides simple and convenient production, transmission, sharing channels and intuitive video presentation, so that viewers have a stronger visual stimulation, and the time to capture, receive and understand the transmitted content information is greatly reduced (Hanson, 2016). The continuous development of $4 \mathrm{G}$ network technology, the popularization of intelligence and the continuous update of mobile terminal shooting equipment all provide the material basis for the short video explosion. The widespread wireless network saves users' mobile data flow, and enables users to have more opportunities to communicate through media and develop closer relationship links. Thus, short video can be social. For production the contents of the momentary user interactions, the user establishes the "one to many" type network-based relationship during forwarding of the original information. Imitation of the original contents takes place in the followers' interactions in the next stage, the additional forwarding processes will link together each original content transforming the "one to many" relationship into a "many-tomany" stable network relationship (Ananthanarayanan et al., 2017).

The role of short video software on mobile terminals is to meet the original needs of the audience, and after this process may bring other additional results and effects. In addition to the unique propagation properties of short videos, the external environment also provides fertile soil for their growth. A series of supportive policies and a large influx of capital for the development of short video in China provide a broader development space for the transmitter and the recipient, and a more fertile soil for the mobile short video application market. For example, Alibaba group has increased its investment in Tudou's live video and Baidu Video. It has injected 500 million yuan to create professional content (Wang, \& Lobato, 2019). All of these have contributed to the development of short videos.

\section{Material and methods}

This paper deals with a quantitative method to identify the core competence of TikTok short video. A specific, multi-level fuzzy comprehensive evaluation method is applied to measure and evaluate the core competence of TikTok. This method will consider two aspects, core resources and capabilities. After identifying the core competence, the fuzzy hierarchy evaluation method (FAHP) was used to create a fuzzy matrix, and an evaluation system was developed for the core competence according to certain indicators ( $\mathrm{Li}$ et al., 2017). Finally, the core competence and competitiveness level of TikTok short video could be obtained through calculation and analysis.

The fuzzy approach appears frequently in the field of modern design evaluation processes. The fundamentals of fuzzy logic were introduced by Zadeh in 1965. This logic can handle those cases where conventional binary logic fails. The other main advantage of fuzzy logic is that the set-up and the work flow in this logic is very similar to human thinking; therefore, it is naturally applicable for analysis if discrete human-human interaction is presented, such as in social networks.

At present, there are three commonly used methods to evaluate core competitiveness: multi-objective comprehensive evaluation method, complex overall evaluation method and simple overall evaluation method. Among them, the third method is mainly to carry out a detailed comparison and discussion on a specific 
influencing factor, and then obtain the corresponding overall assessment results. The socalled complex population evaluation refers to the evaluation object composed of many corresponding multi-seed synthesis that cannot be simply added, and the evaluation result of the whole population can be evaluated by many times of corresponding evaluation results (Feng, Sun, Chen, \& Gao, 2020). The so-called multi-objective evaluation based on the corresponding evaluation index system, in addition to the implementation of the corresponding comprehensive system analysis of the evaluation object, so to obtain the corresponding assessment conclusion. The core competitiveness of an enterprise belongs to the category of multi-objective comprehensive evaluation. In addition, because of its fuzzy and hierarchical characteristics, the multi-level fuzzy comprehensive evaluation method is usually used (Yanrong, Yu, \& Kang, 2011). Fuzzy AHP is the combination of Fuzzy mathematics and analytic hierarchy process (AHP). Taking Fuzzy mathematics as the theoretical basis, it deduces the most likely Fuzzy degree of multiple constraint factors, and then makes the most reasonable decision on problems according to the evaluation target.

In order to obtain relevant opinion data, we selected 21 KOIs (key opinion leaders, hereinafter called experts), mainly based on Feng, Sun, Chen, \& Gao, 2020 Annex 1 in Q4 2020 and Q1 2021.

In order to scientifically evaluate the core competitive power, to ask a lot of areas of short video and the Internet industry stakeholders, in accordance with the principle of easy to measure, easy to obtain, comparability and feasibility, and the combination of the key factors affecting its core competitiveness, set up the trill short video corresponding evaluation index system, the core competitiveness of the main criteria is experts selected level (van Dyck, \& Ismael, 2015). It analyses a complex problem, decomposes it into the combination relation of various factors, and then deduces the hierarchy structure of the evaluation index according to the classification of different subordination relations (Botti \& Peypoch, 2013). By comparing the two levels, the weight of various factors can be obtained.

The core competencies of the corresponding 4 items of the relevant index system are Tik Tok indexes, that is, $\mathrm{A}=(\mathrm{A} 1, \mathrm{~A} 2, \mathrm{~A} 3, \mathrm{~A} 4), \mathrm{A} 1$ to $\mathrm{A} 4$ refer to the four core competencies of the short video content provider companies. For each master criterion layer, its corresponding indexes are composed of many secondary indexes, that is, A1 $=(\mathrm{A} 11, \mathrm{~A} 12, \mathrm{~A} 13, \mathrm{~A} 14), \mathrm{A} 2=(\mathrm{A} 21, \mathrm{~A} 22, \mathrm{~A} 23, \mathrm{~A} 24), \mathrm{A} 3=(\mathrm{A} 31, \mathrm{~A} 32, \mathrm{~A} 33, \mathrm{~A} 34), \mathrm{A} 4=(\mathrm{A} 41$, A42, A43, A44). Here, Aij refers to the secondary indexes of each item.

Table 1.: Core competencies comprehensive evaluation index system

\begin{tabular}{|l|l|l|}
\hline & Core resource-based capabilities & Core resources \\
\hline \multirow{3}{*}{} & A1-internationalization ability & A11-Number of countries \\
& & A12-Number of users in developed countries \\
A13-The number of countries in which the App Store ranks in the top three \\
A14-Overseas mergers and acquisitions
\end{tabular}

Source: own edition 


\section{The specific analysis process}

(1) Determination of index weight

It is assumed that the weights of all the indicators of the four criteria layers to target layer A are P1, P2, P3, and P4, where the weights are not negative, and $\sum_{i=1} p=1$, where the corresponding set is $\mathrm{P}=(\mathrm{P} 1, \mathrm{P} 2, \mathrm{P} 3, \mathrm{P} 4)$. Similarly, the secondary index of the criterion layer here is the set of weights relative to the main criterion layer: $\mathrm{P} 1=(\mathrm{P} 11$, $\mathrm{P} 12, \mathrm{P} 13, \mathrm{P} 14), \mathrm{P} 2=(\mathrm{P} 21, \mathrm{P} 22, \mathrm{P} 23, \mathrm{P} 24), \mathrm{P} 3=(\mathrm{P} 31, \mathrm{P} 32, \mathrm{P} 33, \mathrm{P} 34)$, and $\mathrm{P} 4=(\mathrm{P} 41, \mathrm{P} 42$, $\mathrm{P} 43, \mathrm{P} 44)$, where Pij refers to the weight relation of all secondary indexes relative to several indexes in the main criterion layer. Then the corresponding judgment matrix is constructed.

By comparing the two indexes in the same level, it can be judged that the importance of all indexes in this level relative to the previous level, so as to obtain the corresponding judgment matrix. The m-order judgment matrix is established as $\mathrm{X}=[\mathrm{xi}]$. Xij refers to the degree of importance of the index $\mathrm{xi}$ and $\mathrm{Xj}$ compared to the index at the previous level.

\section{Construction of the set of evaluation levels}

The basic theory of evaluation hierarchy set refers to the set of all evaluation results obtained by researchers through analysis of the evaluation objects. The 1-9 scale method is usually used to study the matrix scale. For the value of the matrix related to the pair judgment, it is based on the actual situation.

Table 2: The Value of X Element in Importance Judgment Matrix

\begin{tabular}{|c|l|}
\hline Scale values & Explanation \\
\hline $\mathbf{1}$ & Both measures are equally important \\
\hline $\mathbf{3}$ & This indicator is slightly more important than the other one \\
\hline $\mathbf{5}$ & This indicator is obviously more important than the other one \\
\hline $\mathbf{7}$ & This metric is very important to the other one \\
\hline $\mathbf{9}$ & This indicator is absolutely more important than the other one \\
\hline 2. 4. 6.8 & The median of the adjacent scales above \\
\hline
\end{tabular}

According to the calculation results of relative weights, it is obtained by the method of product square method, and then the eigenvector and the maximum eigenvalue of the m-order matrix are deduced by it. And then the maximum eigenvalue of the judgment matrix can be calculated.

$$
\lambda_{\max }=\frac{1}{\mathrm{~m}} \sum_{i=1}^{m} \frac{\sum_{j=1}^{m} p_{j} x_{i j}}{p j}
$$

The corresponding consistency test is carried out, because the judgment matrix must undergo consistency test to determine whether the judgment matrix is reasonable or not. The consistency index C.I is as follows:

$$
C . I=\frac{\lambda_{\max }-m}{m-1}
$$


Table 3: Random Consistency Average Index

\begin{tabular}{|l|c|c|c|c|c|c|c|c|c|c|c|c|}
\hline Order & $\mathbf{1}$ & $\mathbf{2}$ & $\mathbf{3}$ & $\mathbf{4}$ & $\mathbf{5}$ & $\mathbf{6}$ & $\mathbf{7}$ & $\mathbf{8}$ & $\mathbf{9}$ & $\mathbf{1 0}$ & $\mathbf{1 1}$ & $\mathbf{1 2}$ \\
\hline R.I & 0 & $\mathbf{1}$ & 0.56 & 0.88 & 1.11 & 1.23 & 1.33 & 1.42 & 1.43 & 1.48 & 1.51 & 1.53 \\
\hline
\end{tabular}

Then the mathematical equation to calculate the index ratio of stochastic consistency C.R is as follows:

$$
C . R=\frac{C . I .}{R . I .}
$$

In general, if C.R $<0.10$, it can be explained that this judgment matrix is applicable to the calculation of random consistency index. On the contrary, if C.R. is $\geq 0.10$, it can be explained that it is not applicable to this index. Therefore, it should be modified to make it less than 0.1 , so as to make it conform to the random consistency index.

(2) Build the set of evaluation levels

The basic theory of evaluation hierarchy set refers to the set of all evaluation results obtained by researchers through analysis of the evaluation objects. $Y=\left(Y_{1}, Y_{2}\right.$, ........, $Y_{m}$ ), where $Y_{j}$ corresponds to the relevant evaluation conclusion of the JTH term, while $\mathrm{m}$ is in accordance to its order. Based on the enterprise core competence and its evaluation index, the evaluation index and core competitiveness of the enterprise are divided into four standards: Extremely Strong, Strong, Average and Poor, that is $\mathrm{m}=4$, $\mathrm{Y}=\left(\mathrm{Y}_{1}, \mathrm{Y}_{2}, \mathrm{Y}_{3}, \mathrm{Y}_{4}\right)=$ (Extremely Strong, Strong, Average and Poor).

(3) Construction of the fuzzy evaluation matrix of first-level indicators

According to the results of the corresponding questionnaire and the opinions given by the experts in the short video, the affiliation relationship between all the factors and all the hierarchical relationships was clarified. In other words, a single factor can be formed into a corresponding vector value of fuzzy evaluation. For example, Rij=(rij1, rij2, rij3, rij4). That is to say, rij1 means starting from item $\mathrm{i}$ while the $\mathrm{j}$ term in the first index corresponds to the second index. The first is about the corresponding membership degree of the evaluation results, $i=1,2,3,4,5,6,7, k, j=1,2,3,4,5,6,7, k$, where $\mathrm{k}$ refers to the number of all secondary indicators under the primary indicator. The fuzzy evaluation matrix is composed of fuzzy evaluation vectors of all single factors.

$$
R_{\mathrm{i}}=\left[\begin{array}{cccc}
R_{\mathrm{i} 11} & R_{i 12} & R_{i 13} & R_{i 14} \\
R_{i 21} & R_{i 22} & \mathrm{R}_{\mathrm{i} 23} & \mathrm{R}_{\mathrm{i} 24} \\
\cdots & \cdots & \cdots & \cdots \\
\mathrm{R}_{\mathrm{ik} 1} & \mathrm{R}_{\mathrm{ik} 2} & \mathrm{R}_{\mathrm{ik} 3} & \mathrm{R}_{\mathrm{ik} 4}
\end{array}\right]
$$

(4) Calculation of the fuzzy vector of the first-order index

The fuzzy vector corresponding to the first-level index can be obtained by multiplying the fuzzy matrix corresponding to the first-level index with the weight matrix related to the lower-level index.

$$
A_{i}=P_{i} \times R_{i}=\left(P_{i 1}, P_{i 2} \ldots, P_{i k}\right) \times\left[\begin{array}{cccc}
r_{i 11} & r_{i 12} & r_{i 13} & r_{i 14} \\
r_{i 21} & r_{i 22} & r_{i 23} & r_{i 24} \\
\ldots & \ldots & \ldots & \ldots \\
r_{\text {ik1 }} & r_{i k 2} & r_{i k 3} & r_{i k 4}
\end{array}\right]=\left(\partial_{1}, \partial_{2}, \partial_{3}, \partial_{4}\right)
$$


(5) Construction of the synthetic fuzzy matrix

The fuzzy vector corresponding to the first-level index can be obtained by multiplying the fuzzy matrix corresponding to the first-level index and the relevant weight matrix of the second-level index at the lower level (Shen \& Barner, 2004).

$$
R=\left[\begin{array}{cccc}
a_{11} & a_{12} & a_{13} & a_{14} \\
a_{21} & a_{22} & a_{23} & a_{24} \\
\cdots & \cdots & \cdots & \cdots \\
a_{81} & a_{82} & a_{83} & a_{84}
\end{array}\right]
$$

(6) Matrix multiplication yields comprehensive fuzzy evaluation results.

The matrix obtained above and the corresponding weight set composed with the first-order index are used to multiply the fuzzy matrix. The fuzzy comprehensive evaluation results can be obtained as shown below:

$$
A=B R=\left(B_{1}, B_{2}, \ldots B_{8}\right)=\left[\begin{array}{cccc}
a_{11} & a_{12} & a_{13} & a_{14} \\
a_{21} & a_{22} & a_{23} & a_{23} \\
\ldots & \ldots & \ldots & \ldots \\
a_{81} & a_{82} & a_{83} & a_{84}
\end{array}\right]=\left(\partial_{1}, \partial_{2}, \partial_{3}, \partial_{4}\right)
$$

\section{Results and discussion}

Core competitiveness of TikTok video

After studying the opinions of experts in the field of Douyin short video on relevant evaluation indexes, and grading its important features, a judgment matrix is established according to the corresponding AHP model. In addition, the AHP model is used to calculate the corresponding weights of the master criterion layer and the corresponding sub-criterion layer (Yang, \& Lee, 1997). Firstly, the weights of the four core competencies in the master criterion of Douyin core competitiveness are judged, namely, internationalization development ability, technology research and development ability, cultural communication ability, and the profit generation ability.

Main Criteria Level:

- A1-internationalization ability

- A2-Technology R\&D ability

- A3-Cultural communication ability

- A4-Profit generation ability

\begin{tabular}{|c|c|c|c|c|c|}
\hline Competitiveness & A1 & A2 & A3 & A4 & weight \\
\hline A1 & 1 & 3 & $3 / 2$ & 9 & 0.5219 \\
\hline A2 & $1 / 3$ & 1 & $1 / 2$ & 3 & 0.1739 \\
\hline A3 & $2 / 3$ & $1 / 2$ & 1 & 6 & 0.2460 \\
\hline A4 & $1 / 9$ & $1 / 3$ & $1 / 6$ & 1 & 0.0579 \\
\hline
\end{tabular}

Table 4: Competitiveness of judgment matrix and weight

Source: Own edition 
For consistency check, it meets the corresponding consistency requirements as C.R. $<0.10$. Therefore, the relevant weight set $\mathrm{P}$ of the master criterion layer relative to the core competitiveness $=(0.5219,0.1739,0.2460,0.0579)$. C.R. $<0.10$, it would meet the corresponding consistency requirements. Therefore, relative weight set $\mathrm{P}$ of the master criterion layer relative to the core competitiveness $=(0.5219,0.1739,0.2460$, $0.0579)$.

The following uses the weight of internationalization ability of the sub Criteria Level to judge the international development capacity:

Table 5: Standard Layer of internationalization ability

\begin{tabular}{|l|l|}
\hline Main Criteria Level & Sub Criteria Level \\
\hline \multirow{4}{*}{ A1 } & A11-Number of countries \\
\cline { 2 - 2 } & A12-Number of users in developed countries \\
\cline { 2 - 2 } & $\begin{array}{l}\text { A13-The number of countries in which the App Store ranks } \\
\text { in the top three }\end{array}$ \\
\cline { 2 - 2 } & A14-Overseas mergers and acquisitions \\
\hline
\end{tabular}

Source: own edition

According to the four criteria in the table by experts, comparison is drawn after scoring:

Table 6: Judgment Matrix and Weight of internationalization ability

\begin{tabular}{|c|c|c|c|c|c|}
\hline Competitiveness & A11 & A12 & A13 & A14 & weight \\
\hline A11 & 1 & $8 / 7$ & $8 / 5$ & $8 / 5$ & 0.32 \\
\hline A12 & $7 / 8$ & 1 & $7 / 5$ & $7 / 5$ & 0.28 \\
\hline A13 & $5 / 8$ & $5 / 7$ & 1 & 1 & 0.2 \\
\hline A14 & $5 / 8$ & $5 / 7$ & 1 & 1 & 0.2 \\
\hline \multicolumn{7}{l}{$\lambda_{\max }=4, C . I=0, C . R=0<0.10$} \\
\hline
\end{tabular}

Source: Own edition

For consistency check, it meets consistency requirements as C.R. $<0.10$. Therefore, the weight set $\mathrm{P}$ of internationalization development ability $=(0.32,0.28,0.2$, $0.2)$.

The following is the weight of Technology R\&D ability of sub Criteria Level to judge the international development capacity.

Table 7. Standard Layer of Technology RED ability

\begin{tabular}{|c|c|}
\hline Main Criteria Level & Sub Criteria Level \\
\hline \multirow{3}{*}{ A2 } & A21-Recommendation algorithm \\
\cline { 2 - 2 } & A22-Maximum concurrent load \\
\cline { 2 - 2 } & A23-Per capita usage time \\
\cline { 2 - 2 } & A24-Number of technical patents \\
\hline
\end{tabular}

Source: Own edition 

is drawn.

According to the four criteria in the table by experts, comparison after scoring

Table 8: Judgment Matrix and Weight of Technology RED ability

\begin{tabular}{|l|c|c|c|c|c|}
\hline Competitiveness & A21 & A22 & A23 & A24 & weight \\
\hline A21 & 1 & $5 / 4$ & $5 / 3$ & $5 / 3$ & 0.333 \\
\hline A22 & $4 / 5$ & 1 & $4 / 3$ & $4 / 3$ & 0.2666 \\
\hline A23 & $3 / 5$ & $3 / 4$ & 1 & 1 & 0.2 \\
\hline A24 & $3 / 5$ & $3 / 4$ & 1 & 1 & 0.2 \\
\hline \multicolumn{7}{|c|}{$\lambda_{\max =\mathbf{4}, \text { C.I }=\mathbf{0 , C . R = 0 < 0 . 1 0}}$} \\
\hline
\end{tabular}

Source: Own edition

In the consistency test, it meets consistency requirements as C.R. $<0.10$. Therefore, the weight set $\mathrm{P}$ of technological development ability $=(0.3333,0.2666,0.2$, $0.2)$

The following is the weight of cultural communication ability of sub Criteria Level to judge the international development capacity.

Table 9: Standard Layer of Cultural Communication Ability

\begin{tabular}{|l|l|}
\hline Main Criteria Level & sub Criteria Level \\
\hline \multirow{4}{*}{ A3 } & A31-Tik Tok music entered the hot music chart \\
\cline { 2 - 3 } & A32-Promote the contribution of local tourism \\
\cline { 2 - 3 } & A33-Mainstream media coverage of the situation \\
\cline { 2 - 2 } & A34-Number of media Numbers \\
\hline
\end{tabular}

Source: own edition

According to the four criteria in the table by experts, comparison after scoring is drawn.

Table 10: Judgment Matrix and Weight of Cultural Communication Ability

\begin{tabular}{|c|c|c|c|c|c|}
\hline Competitiveness & A31 & A32 & A33 & A34 & weight \\
\hline A31 & 1 & $4 / 3$ & $8 / 5$ & 2 & 0.3478 \\
\hline A32 & $3 / 4$ & 1 & $6 / 5$ & $3 / 2$ & 0.2608 \\
\hline A33 & $5 / 8$ & $5 / 6$ & 1 & $5 / 4$ & 0.2173 \\
\hline A34 & $1 / 2$ & $2 / / 3$ & $4 / 5$ & 1 & 0.1739 \\
\hline \multicolumn{6}{|l}{} \\
\hline
\end{tabular}

Source: own edition

In the consistency test, it meets consistency requirements as C.R. $<0.10$. Therefore, the weight set of cultural communication ability is $\mathrm{P}=(0.3478,0.2608,0.2173$, 0.1739). 
The following is the judgment of the weight of sub Criteria Level of profitability ability.

Table 11: Standard Layer of Profitability ability

\begin{tabular}{|c|l|}
\hline Main Criteria Level & Sub Criteria Level \\
\hline \multirow{3}{*}{ A4 } & A41-Number of paying subscribers \\
\cline { 2 - 2 } & A42-Percentage of paying users \\
\cline { 2 - 2 } & A43-Per capita payment amount \\
\cline { 2 - 2 } & A44-Platform advertising profitability \\
\hline
\end{tabular}

Source: own edition

Comparing each two of the four criteria and then the grading can be:

Table 12: Judgment Matrix and Weight of Profitability ability

\begin{tabular}{|l|c|c|c|c|c|}
\hline Competitiveness & A41 & A42 & A43 & A44 & weight \\
\hline A41 & 1 & $3 / 5$ & $3 / 2$ & $3 / 2$ & 0.25 \\
\hline A42 & $5 / 3$ & 1 & $5 / 2$ & $5 / 2$ & 0.4166 \\
\hline A43 & $2 / 3$ & $2 / 5$ & 1 & 1 & 0.1666 \\
\hline A44 & $2 / 3$ & $2 / 5$ & 1 & 1 & 0.1666 \\
\hline \multicolumn{6}{|l}{} \\
\end{tabular}

Source: own edition

In the consistency test, it meets consistency requirements as C.R. $<0.10$. Therefore, the weight set of profitability ability is $\mathrm{P}=(0.25,0.4166,0.1666,0.1666)$. Therefore, the weight set of the relevant master criterion layer relative to the core competitiveness of the company is $\mathrm{P}=(0.5219,0.1739,0.2460,0.0579)$.

The weight set corresponding to all indicators in the sub-criteria layer is:

- International development capacity: $\mathrm{P} 1=(0.32,0.28,0.2,0.2)$

- $\quad$ Cultural communication ability: $\mathrm{P} 3=(0.3478,0.2608,0.2173,0.1739)$

- $\quad$ Profit generation ability: $\mathrm{P}=(0.25,0.4166,0.1666,0.1666)$

The core competitiveness in the field of short video was investigated by means of a questionnaire, and the relevant membership degree of the corresponding second-level evaluation index was statistically obtained. That is to say, its fuzzy evaluation matrix is available.

Table 13: Fuzzy evaluation matrix of short video I industry

\begin{tabular}{|c|c|c|c|c|}
\hline sub Criteria Level & Very strong & Strong & Average & Poor \\
\hline A11 & 0.8 & 0.2 & 0 & 0 \\
\hline A12 & 0.7 & 0.3 & 0 & 0 \\
\hline A13 & 0.7 & 0.3 & 0 & 0 \\
\hline A14 & 0.7 & 0.3 & 0 & 0 \\
\hline A21 & 0.6 & 0.3 & 0.1 & 0 \\
\hline
\end{tabular}




\begin{tabular}{|c|c|c|c|c|}
\hline A22 & 0.7 & 0 & 0.2 & 0.1 \\
\hline A23 & 0 & 0.6 & 0.2 & 0.2 \\
\hline A24 & 0 & 0.5 & 0.5 & 0 \\
\hline A31 & 0.7 & 0.2 & 0.1 & 0 \\
\hline A32 & 0.6 & 0 & 0.4 & 0 \\
\hline A33 & 0.6 & 0.2 & 0.2 & 0 \\
\hline A34 & 0 & 0.7 & 0.2 & 0.1 \\
\hline A41 & 0 & 0.2 & 0.6 & 0.2 \\
\hline A42 & 0 & 0.1 & 0.7 & 0.2 \\
\hline A43 & 0 & 0 & 0.8 & 0 \\
\hline A44 & 0 & 0.1 & 0.9 & \\
\hline
\end{tabular}

Source: own edition

$$
\begin{aligned}
& R_{1}=\left[\begin{array}{cccc}
0.8 & 0.2 & 0 & 0 \\
0.7 & 0.3 & 0 & 0 \\
0.7 & 0.3 & 0 & 0 \\
0.7 & 0.3 & 0 & 0
\end{array}\right] \quad R_{2}=\left[\begin{array}{cccc}
0.6 & 0.3 & 0.1 & 0 \\
0.7 & 0 & 0.2 & 0.1 \\
0 & 0.6 & 0.2 & 0.2 \\
0 & 0.5 & 0.5 & 0
\end{array}\right] \\
& R_{3}=\left[\begin{array}{cccc}
0.7 & 0.2 & 0.1 & 0 \\
0.6 & 0 & 0.4 & 0 \\
0.6 & 0.2 & 0.2 & 0 \\
0 & 0.7 & 0.2 & 0.1
\end{array}\right] \quad R_{4}=\left[\begin{array}{cccc}
0 & 0.2 & 0.6 & 0.2 \\
0 & 0.1 & 0.7 & 0.2 \\
0 & 0 & 0.8 & 0.2 \\
0 & 0.1 & 0.9 & 0
\end{array}\right]
\end{aligned}
$$

Through the analytic hierarchy process, the corresponding weight data of the second-level indicators are obtained, thus the relevant membership degree of each first-level indicator is also available:

$$
\begin{aligned}
& \mathrm{A} 1=\mathrm{P} 1 \times \mathrm{R} 1=(0.32,0.28,0.2,0.2) \\
& \mathrm{A} 2=\mathrm{P} 2 \times \mathrm{R} 2=(0.3333,0.3,0.2,0.2) \\
& \mathrm{A} 3=\mathrm{P} 3 \times \mathrm{R} 3=(0.3478,0.2,0.2608,0.1) \\
& \mathrm{A} 4=\mathrm{P} 4 \times \mathrm{R} 4=(0,0.2,0.4166,0.2)
\end{aligned}
$$

Table 14.: First class core competitiveness evaluation index

\begin{tabular}{|c|c|c|c|c|c|}
\hline $\begin{array}{c}\text { Main } \\
\text { Criteria } \\
\text { Level }\end{array}$ & Very strong & Strong & Average & Poor & $\begin{array}{c}\text { Evaluation } \\
\text { results }\end{array}$ \\
\hline A1 & 0.32 & 0.28 & 0.2 & 0.2 & Very strong \\
\hline A2 & 0.3333 & 0.3 & 0.2 & 0.2 & Very strong \\
\hline A3 & 0.3478 & 0.2 & 0.2608 & 0.1 & Very strong \\
\hline A4 & 0 & 0.2 & 0.4166 & 0.2 & General \\
\hline
\end{tabular}


Thus, the synthetic fuzzy matrix R can be constructed:

$$
R=\left[\begin{array}{cccc}
0.32 & 0.28 & 0.2 & 0.2 \\
0.3333 & 0.3 & 0.2 & 0.2 \\
0.3478 & 0.2 & 0.2608 & 0.1 \\
0 & 0.2 & 0.4166 & 0.2
\end{array}\right]
$$

The weight of the corresponding first-level index in the master criterion layer can be obtained through the analytic hierarchy process. And then the multilevel fuzzy comprehensive evaluation method is used to normalize it to obtain the fuzzy comprehensive evaluation result: $A=(0.32,0.28,0.2460,0.2)$. In other words, the relevant evaluation results of the core competitiveness of Douyin short video are shown in the table below:

Table 15: Core competitiveness of short video evaluation results

\begin{tabular}{|c|c|c|c|c|c|}
\hline The target Level & Very strong & Strong & Average & Poor & $\begin{array}{c}\text { Evaluation } \\
\text { results }\end{array}$ \\
\hline $\begin{array}{c}\text { Tik Tok core } \\
\text { competitiveness }\end{array}$ & 0.32 & 0.28 & 0.246 & 0.2 & Very strong \\
\hline
\end{tabular}

In order to get the strength level of each core competence, FAHP is used to analyze and evaluate five core competences. The following results can be drawn based on the analysis: Tik Tok short video has a relatively strong performance in international development capability, cultural communication capability, technology research and development capability. And it was still at an ordinary level in profitability.

\section{Improvement methods of core competitiveness of Tik Tok short video}

The international development capability of Douyin's international development ability is particularly strong, whose international name is Tik Tok. Due to Tik Tok's continuous success overseas, Douyin short video has now become an outstanding representative of the success of Chinese products going international. At present, Tik Tok takes technology as the focus of its globalization strategy (Beutell, 2020). Tik Tok makes efforts to bring high user experience all over the world taking into consideration local user needs in a so called custom tailored manner. Tik Tok is widely popular among users in Cambodia, Malaysia, Philippines, Thailand, Japan, Vietnam and other countries, and has been ranked top in Google Play and App Store many times. However, there are also negative tendencies. On July 3, 2018, Tik Tok was banned in Indonesia due to the negative impact of its unhealthy contents (Mhalla, Jiang, \& Nasiri, 2020). When global expansion is going on, attention should be paid to local laws and regulations, and the intensity of content auditing should also be strengthened.

Cultural communication capability. Douyin has its own advantage in cultural communication, that is, it has a forward-looking vision. However, the highly centralized mode leads to the serious homogeneity of short videos and high creative cost. At present, Douyin needs to invest significant amounts in cooperation with MCN (Multi-Channel Network) organizations to develop high-quality content, and invests in cooperation with celebrities to shoot short videos (Osgerby, 2020). At present, knowledge short videos are becoming more and more popular. More and more users are creating information and knowledge short videos on Douyin, which is the result of 
market regulation (Chen, Kaye, \& Zeng, 2020). Taking this opportunity, each business in the short video industry begins to make great efforts to develop layout and partition to achieve the balanced development of knowledge and entertainment videos. As far as Douyin is concerned, the product has an obvious positioning, but there are some deficiencies in content partition. Various sections, such as life and knowledge sections, should be made according to the users' preferences.

As for technology R\&D capability, Douyin has an especially strong technical research and development ability, but at the same time, the shortcomings of Douyin are one of the problems worthy of attention. The home page mechanism of "unlimited bottom" is not conducive to the establishment of social relations. Tik Tok is a distribution mode that relies heavily on algorithms, and it is confident in its algorithms, making users browsing an average of 300 posts (Chen, He, Mao, Chung, \& Maharjan, 2019). However, in algorithm logic, popular content will get more recommendations, while it is difficult to get an effective distribution of long-tail content. Therefore, it can be found that the content of Tik Tok is becoming increasingly classified. Even some new media operation summed up 15 modes of Douyin's popular content, such as entertainment of singing and dancing, accomplishments, encouragement, knowledge dissemination, etc. $(\mathrm{Hu}, 2020)$. Users occasionally see similar patterns on Douyin every day. As a result, it should be more creative in innovation in terms of technical algorithms.

Regarding profit generation ability, the Douyin profit model is relatively mature, which has established two major mechanisms of obtaining profits, livestreams gaining gifts from audiences, and providing a platform for other businesses to broadcast advertisements (Wang, Gu, \& Wang, 2019). At present, Douyin has a commercial operation, which allows web celebrities to have a channel. It also faces challenges in making web celebrities to be commercialized in the long run. The ability of producing original content can attract fans and forwards, but it is difficult to obtain more support. For further growth, Douyin should pay attention to professional support for creators, provide advertising platforms on a commercial basis, cooperate with a number of MCNs, offer traffic support, and even send quality talent to MCN organizations (Susilo, 2020).

\section{Future challenges}

User demand management issues: The Tik Tok platform has been full of a large number of copied and plagiarised video content. As the number of creators and contents grows, the platform needs to figure out how to manage the needs of its 600 million daily active users However, this user experience, the short 15-second video constantly stimulates people's excitement, which makes many users spend several hours without realizing it. ( $\mathrm{Lu} \& \mathrm{Lu}, 2019)$. Due to the huge amount of the short videos content, and the increasing pace of everyday life, the majority of people cannot remember exciting moments. (Omar \& Dequan, 2020).

The strict distinction between entertainment and business: With the rapid growth of the short video market and the entry of major Internet companies, the short video industry has also begun to be diversified. In many Douyin accounts with millions of users, a shopping cart button appears. Douyin entered the e-commerce industry by cooperating with Alibaba, the parent company of Taobao.com, which has attracted a lot of attention (Kaye, Chen, \& Zeng, 2020). Industrial participants believe that Douyin is already striding towards the road of consumption upgrading. Commodity buying and selling is the transaction behaviour, which does not exist in parallel with entertainment. 
The video recommendation category is seriously homogenized: The ten-second duration of short videos, which seems simple, in fact, has created high thresholds when creating high-quality content. PGC is scarce, and high-quality UGC is also difficult to come by. The serious lack of original ability is the main reason for the current homogenization of short video content (Ahlse, Nilsson, \& Sandström, 2020). There is a lack of original ability, which leads to the imitation of content, which aggravates the overlap of Douyin short video content. With the proliferation of users, Douyin's social influence is growing, and the risk of the legal compliance of its content is also gradually expanding. (Herrman, 2019). In July 2018, Douyin was ordered to suspend its rectification due to poor supervision. Not only advertising, but also usergenerated content needs to be regulated, involving legal issues, ethnic differences, religious beliefs and other issues. Douyin has actively cooperated and added functions such as risk warning and reporting to the products, and adopted the mechanism of joint review by machine and manual to screen the risk contents (Khattab, M. (2020).

\section{Social, business opportunities}

The distribution of videos over the Internet is drastically transforming how media is consumed and commercialized. In return for the investments in video stream quality, content providers expect less viewer abandonment, more viewer engagement, and a greater fraction of repeat viewers, resulting in greater revenues. The key question for a content provider is whether and to what extent changes in video quality can cause changes in viewer behaviour. Currently, Douyin has several social and business opportunity utilisation modes ( $\mathrm{Li}, 2018)$ :

Sales based on visitors flow: Attracting visitors to the free flow pool for selling products or recruiting agents is the micro e-commerce business model. Douyin also attracts offline stores: offline bricks-and-mortar stores want to increase customer flow by taking pictures of the features of the products. Shop owners or consumers post videos on the Douyin APP marked with store locations for local consumers (Wei \& Chenxi, 2020).

Advertisement revenue: There will be a lot of advertising businesses to take the initiative to come to negotiate advertising cooperation when there is a certain number of fans for Douyin accounts. For example, the Douyin local food channel can help businesses promote featured food, charging thousands to tens of thousands of dollars for a single ad video (Liu, 2020).

Knowledge to profits: This is an important way for "we media" people to cash in. They can share their professional knowledge on Douyin to attract fans, and then make money by selling courses or related services. This is an important way for wemedia to gain revenues (Keane, 2020). Wemedia is a privatized, popularized, automatic transmitter. It takes the form of modernized and digital means to convey formal and informal information to the majority or minorities. Wemedia contains blogs, microblogs, wechat, baidu tieba and forums. It means the carriers that citizens use to publish what they saw with their own eyes, what they heard with their own ears, and what they think in their own heads. The most commonly seen wemedia overseas include Facebook, Twitter, Instagram, Blogger, Youtube, Tumblr, Reddit, and other similar platforms. They share their professional knowledge on Douyin to attract fans, and then make money by selling courses or related services.

Using e-commerce to make profits: Douyin videos would guide users to Taobao.com by an e-commerce window function, and by including goods in videos. To 
directly promote products on Taobao.com and earn commissions from merchants is a $\mathrm{n}$ important project for many people to cash in Douyin.

Play live streaming to win profits: Fan rewards and live streaming e-commerce are how live streaming makes money at present. Earlier, livestreaming made money mainly through fans, but now it has become the first choice for many, because of higher income through selling goods (Hou, 2018).

Selling Douyin accounts: In order to alleviate the shortage of high-quality content, Douyin started to cooperate with TV stations and film and television companies to introduce high-quality short videos, such as films and shows. To attract traffic and users, stars, celebrities and other high-quality PGC have become the object of each short video platform (Bian, \& Zhu, 2020). In terms of UGC, Douyin short video adopts the way of original subsidy and content sharing, in order to stimulate the creative enthusiasm of authors with excellent originality. Douyin short video platform has launched various special effects with the help of AR (Augmented Reality), VR (Virtual Reality) and AI (Artificial Intelligence) technology, delivering technology innovation solutions to win a large number of users (Sun, Zhang, Zhang, \& Luo, 2020). They create value for the society through assistance to creators and some public welfare measures. For example, Douyin and Jinri Toutiao platforms offer audience and traffic advantages, which are available for patients with rare diseases. They support science, promote disease related knowledge, patients with rare disease, medical diagnosis and treatment (Shuilian, Zhigang, \& Yingying, 2019). Furthermore, with the help of the new way of live-streaming e-commerce to order goods, it helped agricultural producers to utilise e-commerce. It starts from exploring the region's own sales ability to involve more farmers. It improves farmers' ability to sell goods, and innovates the agricultural development model to help farmers and to alleviate poverty, and increase the social value and public benefit of media.

Popularization of knowledge: In 2020, during the COVID-19 worldwide pandemic, Tik Tok popularized prevention among ordinary people, so that more people could get to know about viruses and diseases and to protect themselves. Douyin is becoming a new way for the public to learn legal knowledge and seek legal help (He, Hu, Zhou, \& Wu, 2020). Douyin also popularizes waste selection. (Lu \& Lu, 2019). It popularizes waste selection knowledge and spreads the concept of green and healthy life among the public. Users are able to contact with new knowledge, learn new skills, and unknowingly promote the popular science content in entertainment on Douyin APP. (Du, Liechty, Santos, \& Park, 2020).

\section{Conclusion}

The increasingly improved standard of living can contribute to a higher degree of market attention and competition in the short video market. The short video industry will have more opportunities, while market competition will be significantly stronger. In order to win corporate competition and occupy more market share, Douyin must develop its core competitiveness and cultivate more talent. Through continuous learning and exploration, they need to grasp the industry quality resources and cultivate excellent production ability. For this purpose, based on the relevant theories of core competitiveness, this paper focused on analysis to distinguish the core resources and core capabilities of Douyin, and used the multi-level fuzzy comprehensive evaluation method to judge the current competitiveness level of Douyin, and puts forward a series of measures to develop their core competitiveness 
(profit generation ability, cultural communication ability, technology research and development ability and international development ability.). The challenges, social and business opportunities of Douyin in the future were analysed. At the same time, this paper also analyses the business opportunities of the short video market: new realization mode, obtaining better traffic, creating more social value to promote economic development, knowledge popularization, etc. According to the above research work, Douyin must improve its core competitiveness in the future development process.

Obviously we faced a number of limitations in our study, e.g. including other descriptors (geographic location, occupation/function, etc.) that we plan to make up for in future research.

Some key factors contributing to the rise of short video apps include Chinese users' growing demand for more accessible and easier entertainment content. Video length and the connection between short-video and e-commerce are expected to grow in 2021. Douyin has already allowed longer videos as part of a push to deepen content quality and expand usage. Just as in the case of everything else digital in 2020, the pandemic has accelerated development and short-video consumption grew. While many are calling for stricter regulation, the short video market still has a lot of potential to grow. Having succeeded in capturing the attention of China's Internet users at an unprecedented speed, ByteDance will look to support the initiatives of cultural institutions and individual creators in continuing to create the type of culture-centric video that Douyin users have already shown a passion for.

\section{Bibliography}

1. Ahlse, J., Nilsson, F., \& Sandström, N. (2020). It's time to TikTok: Exploring Generation Z's motivations to participate in\# Challenges.

2. Ananthanarayanan, G., Bahl, P., Bodík, P., Chintalapudi, K., Philipose, M., Ravindranath, L., \& Sinha, S. (2017). Real-time video analytics: The killer app for edge computing. Computer, 50(10), 58-67.

3. Beutell, J. M. (2020). Children's rights and social media: An analysis of TikTok's Terms of Service through the lens of a young user.

4. Bian, R., \& Zhu, M. (2020). The Relationship between Ritual, Personal Involvement and Travel Intention: A Study of Check-in-Travel on DouYin. American Journal of Industrial and Business Management, 10(02), 451.

5. Botti, L., \& Peypoch, N. (2013). Multi-criteria ELECTRE method and destination competitiveness. Tourism Management Perspectives, 6, 108-113.

6. Chen, X., Kaye, D. B. V., \& Zeng, J. (2020). \# PositiveEnergy Douyin: constructing "playful patriotism" in a Chinese short-video application. Chinese Journal of Communication, 1-21.

7. Chen, T., \& Lee, H. M. (2014). Why do we share? The impact of viral videos dramatized to sell: How microfilm advertising works. Journal of Advertising Research, 54(3), 292-303.

8. Chen, Z., He, Q., Mao, Z., Chung, H. M., \& Maharjan, S. (2019, May). A study on the characteristics of douyin short videos and implications for edge caching. Proceedings of the ACM Turing Celebration Conference-China (pp. 1-6).

9. Du, X., Liechty, T., Santos, C. A., \& Park, J. (2020). 'I want to record and share my wonderful journey': Chinese Millennials' production and sharing of short-form travel videos on TikTok or Douyin. Current Issues in Tourism, 1-13. 
10. Feng, B., Sun, K., Chen, M., \& Gao, T. (2020). The Impact of Core Technological Capabilities of High-Tech Industry on Sustainable Competitive Advantage. Sustainability, 12(7), 2980.

11. Granic, I., Lobel, A., \& Engels, R. C. (2014). The benefits of playing video games. American psychologist, 69(1), 66.

12. Green, M., Bobrowicz, A., \& Ang, C. S. (2015). The lesbian, gay, bisexual and transgender community online: discussions of bullying and self-disclosure in YouTube videos. Behaviour \& Information Technology, 34(7), 704-712.

13. Gulacti, U., Lok, U., Hatipoglu, S., \& Polat, H. (2016). An analysis of WhatsApp usage for communication between consulting and emergency physicians. Journal of medical systems, 40(6), 130.

14. Gygli, M., Song, Y., \& Cao, L. (2016). Video2gif: Automatic generation of animated gifs from video. Proceedings of the IEEE Conference on Computer Vision and Pattern Recognition (pp. 1001-1009).

15. Hanson, R. E. (2016). Mass communication: Living in a media world. Sage Publications.

16. He, J., Hu, M., Zhou, Y., \& Wu, D. (2020, June). LiveClip: towards intelligent mobile short-form video streaming with deep reinforcement learning. Proceedings of the 30th ACM Workshop on Network and Operating Systems Support for Digital Audio and Video (pp. 54-59).

17. Herrman, J. (2019). How TikTok is rewriting the world. The New York Times, 10.

18. Hou, L. (2018). Study on the perceived popularity of TikTok.

19. Hu, Y. (2020). Research on the commercial value of Tiktok in China. Academic Journal of Business \& Management, 2(7).

20. Kaye, D. B. V., Chen, X., \& Zeng, J. (2020). The co-evolution of two Chinese mobile short video apps: Parallel platformization of Douyin and TikTok. Mobile Media \& Communication, 2050157920952120.

21. Keane, M. (2020). Cultures of creativity and innovation in greater China. Handbook on the Geographies of Creativity. Edward Elgar Publishing.

22. Khattab, M. (2020). Synching and performing: body (re)-presentation in the short video app TikTok.

23. Krishnan, S. S., \& Sitaraman, R. K. (2013). Video stream quality impacts viewer behavior: inferring causality using quasi-experimental designs. IEEE/ACM Transactions on Networking, 21(6), 2001-2014. https:/ / doi.org/10.1.1.370.4186

24. Li, J. (2018). Studies on Douyin app Communication in Social Platforms: Take Relevant Douyin Short Videos and Posts on Microblog as Examples.

25. Li, W., Yu, S., Pei, H., Zhao, C., \& Tian, B. (2017). A hybrid approach based on fuzzy AHP and 2-tuple fuzzy linguistic method for evaluation in-flight service quality. Journal of Air Transport Management, 60, 49-64.

26. Liu, Y., Lyu, C., Liu, Z., \& Tao, D. (2019). Building Effective Short Video Recommendation. 2019 IEEE International Conference on Multimedia \& Expo Workshops (ICMEW) (pp. 651-656). IEEE.

27. Lu, X., \& Lu, Z. (2019). Fifteen Seconds of Fame: A Qualitative Study of Douyin, A Short Video Sharing Mobile Application in China. International Conference on Human-Computer Interaction (pp. 233-244). Springer, Cham.

28. Ma, L., Feng, J., Feng, Z., \& Wang, L. (2019). Research on User Loyalty of Short Video App Based on Perceived Value-Take Tik Tok as an Example. In 2019 16th International Conference on Service Systems and Service Management (ICSSSM) (pp. 1-6). IEEE. 
29. Masiar, A., \& Simko, J. (2015). Short video metadata acquisition game. In 2015 10th International Workshop on Semantic and Social Media Adaptation and Personalization (SMAP) (pp. 1-5). IEEE.

30. Mhalla, M., Jiang, Y., \& Nasiri, A. (2020). Video-Sharing Apps Business Models: TikTok Case Study. International Journal of Innovation and Technology Management.

31. Omar, B., \& Dequan, W. (2020). Watch, share or create: The influence of personality traits and user motivation on TikTok mobile video usage.

32. Osgerby, B. (2020). Youth Culture and the Media: Global Perspectives. Routledge.

33. Shen, Y. \& Kenneth Barner (2004): Fuzzy Vector Median-Based Surface Smoothing IEEE Transactions on Visualization and Computer Graphics 10(3):252-265 https:/ / doi.org/10.1109/TVCG.2004.1272725

34. Shuilian, W., Zhigang, L., \& Yingying, D. (2019). Research on Value Creation Process Model of Shared Economic Platform - A Case Study of Didi, Airbnb and Douyin. Management Review, 31(7), 45.

35. Sun, L., Zhang, H., Zhang, S., \& Luo, J. (2020). Content-based Analysis of the Cultural Differences between TikTok and Douyin. arXiv preprint arXiv:2011.01414.

36. Susilo, D. (2020). Unlocking The Secret of E-Loyalty: A Study from Tiktok Users in China. International Journal of Economics, Business, and Entrepreneurship (IJEBE), 3(1), 37-49.

37. Trzciński, T., Andruszkiewicz, P., Bocheński, T., \& Rokita, P. (2017). Recurrent neural networks for online video popularity prediction. International Symposium on Methodologies for Intelligent Systems, pp. 146-153. Springer, Cham.

38. van Dyck, G. K., \& Ismael, H. M. (2015). Multi-criteria evaluation of port competitiveness in West Africa using analytic hierarchy process (AHP). American Journal of Industrial and Business Management, 5(06), 432.

39. Wang, Y. H., Gu, T. J., \& Wang, S. Y. (2019). Causes and Characteristics of Short Video Platform Internet Community Taking the TikTok Short Video Application as an Example. 2019 IEEE International Conference on Consumer ElectronicsTaiwan (ICCE-TW) (pp. 1-2). IEEE.

40. Wang, Y. (2020a). Influence of camera view on TikTok users' presence, immersion, and adoption intent. Computers in Human Behavior, 106373.

41. Wang, Y. (2020b). Influence of camera view on TikTok users' presence, immersion, and adoption intent. Computers in Human Behavior, 106373.

42. Wang, W. Y., \& Lobato, R. (2019). Chinese video streaming services in the context of global platform studies. Chinese Journal of Communication, 12(3), 356-371.

43. Wei, B., \& Chenxi, L. (2020). Study on the Win-Win Strategy of Douyin and Its Users. In 2020 IEEE 3rd International Conference on Information Systems and Computer Aided Education (ICISCAE) (pp. 183-186). IEEE.

44. Winkler, P., Janoušková, M., Kožený, J., Pasz, J., Mladá, K., Weissová, A.\& Evans-Lacko, S. (2017). Short video interventions to reduce mental health stigma: a multi-centre randomised controlled trial in nursing high schools. Social psychiatry and psychiatric epidemiology, 52(12), 1549-1557.

45. Yang, J., \& Lee, H. (1997). An AHP decision model for facility location selection. Facilities. Vol. 15 No. 9/10, pp. 241-254. https://doi. org/10.1108/02632779710178785

46. Yanrong, W., Yu, L., \& Kang, L. (2011). Evaluation on the Competitiveness of High-tech Entrepreneurial Enterprises. Energy Procedia, 5, 684-689. 


\section{Correspondence address:}

Dr. Zoltán Peredy, Head of Engineering Institute, Edutus University, 2800 Tatabánya, Stúdium tér 1., Hungary, e-mail: peredy.zoltan@edutus.hu;

Feierzhati Fukati, MSc. learner on Business Administration and Management, Edutus University, 1114 Budapest, Villányi út 11-13, Hungary, e-mail: 1173227568@qq.com; or ferzat@foxmail.com;

Balázs Laki, master instructor, Engineering Instritute, Edutus University, 2800 Tatabánya, Stúdium tér 1., Hungary, e-mail: laki.balazs@edutus.hu; 